\title{
About the past, the present and the future of R\&D
}

\author{
Claudio Baccarani - Jeff Butler - Alberto Di Minin \\ Andrea Piccaluga - Roberto Vona
}

Back in the 1990s there was a very nice and lively debate, among management scholars and practitioners, about the future of Research and Development (R\&D) activities. The Science Policy Research Unit (SPRU) of the University of Sussex, in Brighton, was at the heart of this debate and a number of brilliant economists of innovation were inspiring and starting several new research fields which eventually became the backbone of a relevant part of innovation studies in economics and management.

Within that group of scholars there was also someone who was particularly active in visiting companies and creating a sort of intellectual bridge between theoretical and numbers-based academic studies and what was concretely being discussed by industrial managers with regard to innovation. His name was Roy Rothwell and some of his contributions are still heavily cited. Unfortunately, there is a sad tendency to "reinvent the wheel", which often attributes excessive emphasis to the most recent scientific contributions which, in many cases, are based on fundamental works of the recent past that are not always adequately cited.

Among many others, Prof. Rothwell's work on the "fifth generation R\&D" represented an extremely valuable contribution in highlighting the fact that industrial, private R\&D was opening up and getting increasingly connected with a number of external players. Rothwell's contribution, together with Gibbon's "Mode 1 and Mode 2" framework, can be considered among the most important pillars which, directly and indirectly, later allowed Henry Chesbrough to build the rightly renown "Open Innovation" model.

The SPRU group and the Manchester Business School's R\&D Research Unit led by Alan Pearson were among the most inspiring elements of the R\&D Management community which met - both intellectually and physically - through the R\&D Management Journal and the R\&D Managament Conference.

Both the journal and the conference have been accurately studying - and often anticipating - the evolution of R\&D activities in both the private and the public sectors. Among such evolutions, scholars and practitioners have been discussing, in the last two-three decades, the transition from mainly closed $\mathrm{R} \& \mathrm{D}$ organisations to heavily open $\mathrm{R} \& \mathrm{D}$ structures.

The most recent evolution in these fields has occurred at an incredibly fast pace and scholars find it really hard, but at the same time extremely stimulating, to understand what is taking place in companies and universities and advise managers on what they should do in order to gain competitive advantage. 
sinergie Vol. 34, N. 101, 2016

The present special issue of the Sinergie Italian Management Journal aims to provide a contribution in this direction. It is based on the selection of papers presented at the R\&D Management Conference which was held in Pisa in June 2015. The result is a collection of five articles which all regard the evolution of R\&D activities and their interconnection with Open Innovation dynamics.

The papers show a mix of methodological approaches, since three of them are mainly quantitative, one is qualitative and one is theoretical. Three of them regard specific economic sectors, i.e. the aerospace, pharmaceutical and cultural sectors, whereas the two others regard entrepreneurship and university-industry collaborations respectively. All of them pursue rigorous methodologies but at the same time strive to provide relevant managerial implications, and this is a feature which was considered important for their choice

The first contribution - "Open within a box: an analysis of open innovation patterns within Canadian aerospace companies" by Armellini, Beaudry and Kaminski - investigates whether and how aerospace firms in Quebec (Canada) adopt open innovation practices within their R\&D strategies. The paper is built around data collected from the R\&D senior managers of 31 companies in Quebec. The results indicate that innovation in the aerospace sector seems to be product-oriented, with low adoption of formal intellectual-property (IP) protection mechanisms if compared to other forms of protection such as secrecy and complexity of design. Nonetheless, significant evidence of external collaborations was found, ranging from external sourcing to co-development. The picture which emerges is therefore that of a sector in which companies collaborate but do not show relevant collaboration flows outside of the consolidated industry boundaries. Such a contribution is interesting because it accurately describes what is happening in this specific industrial sector, but also generates questions for the future. Will R\&D dynamics in the next few years also foster new kinds of collaboration?

A second quantitative paper on a specific industrial sector, with the aim of exploring collaborations with different types of partners, is the one by Parente, Feola, Cucino and Gimigliano. In their "R\&D Management in Pharma Industry: the strategic role of CROs" the authors claim that the Pharma Industry (PI) has undergone radical changes in R\&D management in recent years. It is estimated that between one third and half of every dollar spent on R\&D by Pharma companies now goes to Contract Research Organizations (CROs). After a systematic literature review on the structural changes affecting this industrial sector, data have been gathered on Italian CROs. The study highlights that CRO development was driven mainly by large pharma outsourcing strategies at first. Nowadays however, CROs also represent an ideal, ready-to-use technological infrastructure for small emerging biotech companies. Moreover, the authors have identified four business models that describe CROs' strategic approach, i.e. a transactional outsourcing model, a functional outsourcing model and a virtual outsourcing model divided into "mode 1" and "mode 2".

New types of collaboration are also explored by Capone and Lazzeretti in their study entitled "Interorganisational networks and proximity: An 
analysis of R\&D networks for cultural goods", in which the authors have attempted to measure the impact of various dimensions of proximity in forming innovation networks. They used a novel statistical methodology for modelling networks on the basis of a well-studied class of models called exponential-family random graph models. Their results underline the importance of various forms of proximity in the formation of innovation networks and the potential of such novel methodology to study large and complex networks in innovation studies and R\&D management. The authors study an economic sector which is often mentioned, but not analysed so much in Italy, that is the cultural goods sector.

Small firms, and more precisely start-ups and their entrepreneurs, are the object of a theoretical study by Leonelli, Ceci and Masciarelli. In their 'The importance of entrepreneurs' traits in explaining start-ups' innovativeness", the authors argue that several studies prove the existence of a relationship between entrepreneurs' personality traits and firms' performances. However, only a few of them focus on how these personality traits can be correlated with start-ups' innovativeness. The authors suggest that entrepreneurs positively influence start-ups' innovativeness whenever they are narcissistic, and have a high level of extraversion, agreeableness, conscientiousness, openness to experience and internal locus of control. In contrast, entrepreneurs with a high level of neuroticism and external locus of control negatively influence start-ups' innovativeness.

Finally, Severinsson, Forsberg and Baraldi, in their "Creating UniversityIndustry Interactions: How can University Management Connect Various Types of Interactions?", claim that University-Industry interactions (U-I interactions) such as joint collaboration projects are currently perceived as an important answer to innovation. However, while in search of detailed descriptions and analyses of U-I interactions, and especially of universities' efforts to create such interactions from the beginning, that is, before they become established relationships, the authors used an embedded case study methodology comprising of participant observation and over 60 in-depth semi-structured interviews on two interaction-stimulating tools employed by a distinguished Swedish university. The authors tried to addresses two research questions: 1) which different types of U-I interactions are created by these tools? and, 2) how does the university management connect these different types of U-I interactions? As regards the first question, it emerged that four types of U-I interactions were created, namely "participation", "cooperation", "collaboration" and "relationship". Regarding the second question, creating successful U-I interactions requires the university management to intervene on all the various interaction types although achieving deeper and long-term interactions may be hindered by the companies' and academic researchers' emphasis on simply exchanging knowledge or building contact networks rather than gaining tangible outputs from U-I interactions.

We would like to thank all the Chairs and the reviewers of the R\&D Management Conference 2015, the colleagues and the practitioners who attended the Conference. 


\section{sinergie} Vol. 34, N. 101, 2016

\section{Academic or professional position and contacts}

\section{Claudio Baccarani}

Full Professor of Management

University of Verona - Italy

e-mail: claudio.baccarani@univr.it

\section{Jeffrey Butler}

Area Editor, Special Topics, Technovation

e-mail: jeff.butler.manchester@gmail.com

\section{Alberto Di Minin}

Associate Professor of Management

Scuola Superiore Sant'Anna of Pisa - Italy e-mail: a.diminin@sssup.it

\section{Andrea Piccaluga}

Full Professor of Management

Scuola Superiore Sant'Anna of Pisa - Italy

e-mail: andrea.piccaluga@sssup.it

\section{Roberto Vona}

Full Professor of Management

University of Napoli Federico II - Italy

e-mail: roberto.vona@unina.it

sinergie italian journal of management

ISSN 0393-5108 DOI 10.7433/s101.2016.01 pp. $9-12$

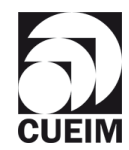

